\title{
CORRECTION
}

\section{Postnatal exposure to household disinfectants, infant gut microbiota and subsequent risk of overweight in children}

CMAJ has been made aware of an error in an article published in the Sept. 17, 2018, issue. ${ }^{1}$ An author's name was misspelled as Tim K. Takarao; the correct spelling is Tim K. Takaro.

This has been corrected at cmaj.ca.

- Cite as: CMAJ 2018 November 12;190:

E1341. doi: 10.1503/cmaj.181432

\section{Reference}

1. Tun MH, Tun HM, Mahoney JJ, et al. Postnatal exposure to household disinfectants, infant gut microbiota and subsequent risk of overweight in children. CMAJ 2018;190:E1097-107. 